\title{
Morphological, Rheological and Mechanical Properties of Pla-Typha Based Biocomposites
}

\author{
Babacar Niang1, Nicola Schiavone², Haroutioun Askanian², Diène Ndiaye ${ }^{1}$, Vincent Verney² \\ ${ }^{1}$ Section de Physique Appliquée, Unité de Formation et de Recherche de Sciences Appliquées et de Technologies, Université \\ Gaston Berger, Saint-Louis, Sénégal \\ ${ }^{2}$ Université Clermont Auvergne, Centre National de la Recherche Scientifique, SIGMA Clermont, Institut de Chimie de Clermont \\ Ferrand, Clermont-Ferrand, France \\ Email: niang.babacar1@ugb.edu.sn
}

How to cite this paper: Niang, B., Schiavone, N., Askanian, H., Ndiaye, D. and Verney, V. (2021) Morphological, Rheological and Mechanical Properties of Pla-Typha Based Biocomposites. Open Journal of Composite Materials, 11, 111-122.

https://doi.org/10.4236/ojcm.2021.114009

Received: January 30, 2020

Accepted: October 26, 2021

Published: October 29, 2021

Copyright (c) 2021 by author(s) and Scientific Research Publishing Inc. This work is licensed under the Creative Commons Attribution International License (CC BY 4.0)

http://creativecommons.org/licenses/by/4.0/

\section{Open Access}

\begin{abstract}
Due to the demand from society for the consumption of ecological polymeric materials, one of the polymers that have satisfied this request is the poly (lactic acid) (PLA). This polymer is derived from renewable resources, it is recyclable and biodegradable. It presents a good understanding between the promising properties and the cost. However, a route to increase the mechanical properties and reduce the cost of PLA is the elaboration of PLA based biocomposites by using fillers from natural waste. In this work, The effect of Typha content on the morphological, rheological, thermal and mechanical properties of PLA matrix was studied. Four formulations were produced with different mass concentrations. The results showed an increase in the viscoelastic properties, as a function of the Typha stem powder concentration. The DSC analysis showed an increase in the crystallinity rate of the various composites confirming the nucleating effect provided by the filler. TGA analysis indicated a decrease in the decomposition temperature of the composites. Mechanical tensile tests have shown a significant improvement in the mechanical properties mainly for the samples containing $45 \%(\mathrm{w} / \mathrm{w})$ of Typha powder.
\end{abstract}

\section{Keywords}

Wood Polymer Composites, Polylactic Acid, Rheology, SEM

\section{Introduction}

The demand by consumers of wood polymer composites (WPC) is having an important increase. At the same time, there was a consequent increase in the products manufactured from WPC and this phenomenon has aroused interest 
on the part of plastic manufacturing companies [1]. The main advantage of using WPC composites is a reduction in the cost of final products. In addition to their biodegradability, they have other important properties, such as high specific stiffness, low density, renewal capacity [2] [3] [4]. Furthermore, an increasingly important interest takes into consideration the aesthetic values of these composites. In fact, the products made with a composite having a large fraction of fillers have an appreciated appearance of the surface and particular sensation to the touch. This characteristic distinguishes them compared to traditional polymers. At the same time, due to their much higher resistance to atmospheric factors compared to wood, the WPCs materials are very widely used as a wood substitute for making terraces, platforms or building facades [1]. Due to their ecological nature, the polymers from renewable resources have received considerable attention; in addition to the risks of futuristic shortages has been increased demand by the consumer society for environmentally friendly products. It is within this framework, that biodegradable poly (lactic acid) (PLA) seems to be one of the best alternatives among all biopolymers with its promising thermal and mechanical properties as well as its low cost [5] [6] [7]. This bioplastic can be produced from renewable resources such as maize and cassava and can be biodegraded naturally into $\mathrm{H}_{2} \mathrm{O}$ and $\mathrm{CO}_{2}$ [8] [9]. However, these composites have a limited number of applications because of different factors as slow crystallization kinetic, easy aging, low rigidity and high product cost. To solve these problems different types of fillers have been combined with polymer matrices to increase the thermal and mechanical properties of biocomposites [10] [11]. This work focuses on the study of Typha australis stem powder biocomposite material without the use of any kind of chemical compatibilizers. Typha australis is an aquatic plant, found on wetlands, and belongs to the family Typhaceae. It is particularly widespread in the valley of the Senegal River. This plant can reach a height of 3 meters [12] and moreover, it turns out to be harmful for agricultural production because of its invasive nature and source of pests [13]. It is used for the construction of wetlands for ecological restoration, wastewater treatment and is also the raw material for weaving paper because of its fiber length, toughness, and heat preservation performance [14] [15] [16] [17]. In this work, the morphological, thermal, rheological, and mechanical properties of biocomposites based on Typha stem powder (TSP) and Poly (lactic acid) (PLA) were studied. The relationship between the powder-mass ratio and the properties of biocomposites was analyzed.

\section{Experimental}

\subsection{Materials}

Poly (lactic acid) (PLA) is a thermoplastic polyester produced by fermentation of renewable agricultural raw materials followed by polymerization. In this study, it has been used the PLLA (PLA4032D), which contained $2 \mathrm{wt} \%$ D-lactic acid and the average molecular weight was 190,000 . It was purchased by Nature Works 
LLC. The density, melting point (Tm) and glass transition temperature of the PLA4032D were $1.24 \mathrm{~g} / \mathrm{cm}^{3}, 170^{\circ} \mathrm{C}$, and $59.2^{\circ} \mathrm{C}$, respectively. The natural filler used was the Typha stem powder. It was collected on the Senegal River banks, in Bango in the region of Saint Louis. The plant was been cut and dried in the air then it undergoes mechanical grinding to transform the stems into powders.

\subsection{Compounding and Processing}

The Typha stem powder was oven-dried at $105^{\circ} \mathrm{C}$ and the PLA at $60^{\circ} \mathrm{C}$ for 24 hours to remove moisture. The composites were elaborated in a HAAKE Minilab twin-screw extruder (Thermo Scientific), operated at a screw speed of 100 $\mathrm{rpm}$, at a temperature of $180^{\circ} \mathrm{C}$ for $5 \mathrm{~min}$. Four formulations of the composites were prepared with different content of filler equal to $0 \%, 25 \%, 35 \%, 45 \%$ in mass of TPS. The composites were then compression molded using a Carver laboratory press at $180^{\circ} \mathrm{C}$ and 200 bar for 1 minute to obtain a film of about 150 $\mu \mathrm{m}$. The film is used for the mechanical test.

\section{Characterization}

\subsection{Morphological Characterization}

A HIROX SH4000M scanning electron microscope (SEM) was used. The samples were fractured in liquid nitrogen and after sputter-coated with gold under an argon gas flow for $15 \mathrm{~min}$. The coated samples were left to dry at room temperature before SEM could be performed. The SEM analyses were done at $20 \mathrm{kV}$ and at a range of magnification equal at $\times 80$ to $\times 150$.

\subsection{Thermal Analysis}

\subsubsection{Thermogravimetric Analysis (TGA)}

To study the thermal degradation process of biocomposites, a TGA analysis was performed. A Mettler Toledo machine operating under a nitrogen atmosphere $\left(20 \mathrm{ml} / \mathrm{min}\right.$ ) has been used for this purpose. The samples were analyzed at $30^{\circ} \mathrm{C}$ $-600^{\circ} \mathrm{C}$ with a heating rate of $10^{\circ} \mathrm{C} / \mathrm{min}$ and a mass of $\approx 20 \mathrm{mg}$ was used for each sample.

\subsubsection{Differential Scanning Calorimetry Analysis}

Thermal analysis of the biocomposite samples was carried out on a differential scanning calorimeter (METTLER TOLEDO DSC 3). All DSC measurements were performed with powdered samples of about $10 \pm 0.2 \mathrm{mg}$ under a nitrogen atmosphere with a flow rate of $20 \mathrm{ml} / \mathrm{min}$. All samples were subjected to the same thermal experiment with the following thermal protocol:

1) First, the samples were heated from $25^{\circ} \mathrm{C}$ to $210^{\circ} \mathrm{C}$ at a heating rate of $10^{\circ} \mathrm{C} /$ min to eliminate any thermal history effect;

2) Second, the samples were cooled from $210^{\circ} \mathrm{C}$ to $40^{\circ} \mathrm{C}$ at a cooling rate of $10^{\circ} \mathrm{C} /$ min to detect the crystallization temperature ( $\mathrm{Tc}$ );

3) Finally, the samples were heated from $25^{\circ} \mathrm{C}$ to $210^{\circ} \mathrm{C}$ at a heating rate of 
$10^{\circ} \mathrm{C} / \mathrm{min}$ to determine $T_{m} . T_{m}$ and the heat of fusion $\left(\Delta H_{m}\right)$ were obtained from the thermograms during the second heating. The values of $\Delta H_{m}$ were used to estimate the crystallinity degree $\left(X_{c}\right)$. The degree of crystallinity $\left(X_{c}\right)$ of the PLA component was determined from the following equation [16] [17]:

$$
X_{c}=\frac{\Delta H_{m}-\Delta H_{c}}{\Delta H_{0} \times(1-w \% T S P)} \times 100
$$

where $\Delta H_{m}, \Delta H_{c}$ and $\Delta H_{0}$ are the heat of fusion of the composites, cold crystallization and PLA $100 \%$ crystalline, respectively. The $w \%$ TSP is the percentage of Typha stem powder. For the PLA $\Delta H_{0}$ is taken to be $93(\mathrm{~J} / \mathrm{g})[18]$.

\subsection{Rheological Characterization}

The viscoelastic behavior of molten polymers can be determined using oscillatory rheological experiments such as dynamic mechanical testing, which offers a convenient way to assess the frequency dependence of mechanical properties of polymers. A useful representation is to plot the experimental frequency sweep data points in the complex plane. That means that imaginary part (of the complex viscosity) $\eta^{\prime}$ values are reported along the abscissa (X axis) and the real ones $\left(\eta^{\prime \prime}\right)$ on the ordinate (Y axis) as schematized in Figure 1; where $\eta^{\prime}$ is the loss viscosity, $\eta^{\prime \prime}$ is the storage viscosity and $\omega$ is the pulsation of the frequency: $\omega=2 \pi \mathrm{N}$. Usually, the experimental points are located on an arc of circle characteristic for a ColeCole distribution. The extrapolation of this arc of circle to the zero ordinate value gives the Newtonian viscosity which is related to the average molecular weight $\mathrm{Mw}$ of the considered polymer through a power law: $\left(\eta_{0}=\mathrm{K}(\mathrm{Mw})^{3.4}\right)$ [17].

Melt rheological measurements of neat PLA and PLA composites were carried out with an ARES Rheometer Scientific mechanical spectrometer in oscillatory frequency sweep mode with a parallel-plates measuring cell. The diameter of the plates was $8 \mathrm{~mm}$ and the gap was $1-1.5 \mathrm{~mm}$. The frequency was ranged from $0.1 \mathrm{rad} / \mathrm{s}$ to $100 \mathrm{rad} / \mathrm{s}$. Deformation was kept constant at $5 \%$ over the entire frequency range to ensure linearity. This strain was selected from a dynamic strain sweep test, in which, within $1 \%$ to $10 \%$ of strains, at a fixed frequency of 10 $\mathrm{rad} / \mathrm{s}$, the drift deviation from linearity was followed; the frequency sweep test was then carried out at a constant temperature at $180^{\circ} \mathrm{C}$.

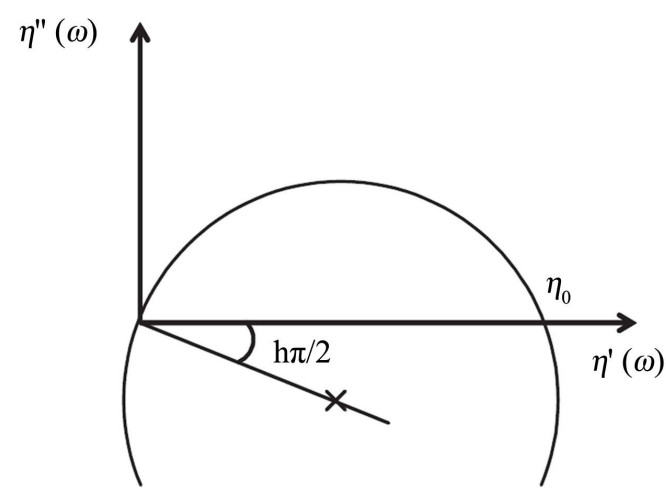

Figure 1. Cole-cole scheme. 


\subsection{Mechanical Properties}

The apparatus used is a Lloyd EZ 50 traction bench. The results are analyzed using the software: NEXYGEN. The tensile strength and elongation at break of the composite were measured according to the ASTM D638-10 method at a crosshead speed of $30 \mathrm{~mm} / \mathrm{min}$. Each sample was subjected to at least 5 repetitive tests to obtain an average.

\section{Results and Discussions}

\subsection{Morphological Characterization}

The cross-sectional topography of PLA/TSP composites and TSP were observed by scanning electron microscopy. It can be observed from Figure 2(a) the differences in shape and size of the particles which constitute the TSP. The shape of powder ranges from particles of approximately spherical geometry lower than 50 microns, going up to filaments more than $1 \mathrm{~mm}$. The large distribution of the particles, in terms of size and shape, reflects on the dispersion in the PLA matrix. As shown in Figures 2(b)-(d) a randomly orientation in the three directions of space and a phase separation between the TSP and matrix was rough with grooves and holes. In fact, in the tensile test, some TSP fibers could be extracted directly from the PLA matrix, indicating that the poor mechanical properties mainly resulted from the poor interfacial adhesion (mechanical test-Section 4.4). In addition, the presence of gaps between the pores and the two phases indicated that the motion of PLA molecules was restricted by poor interfacial compatibility [19].

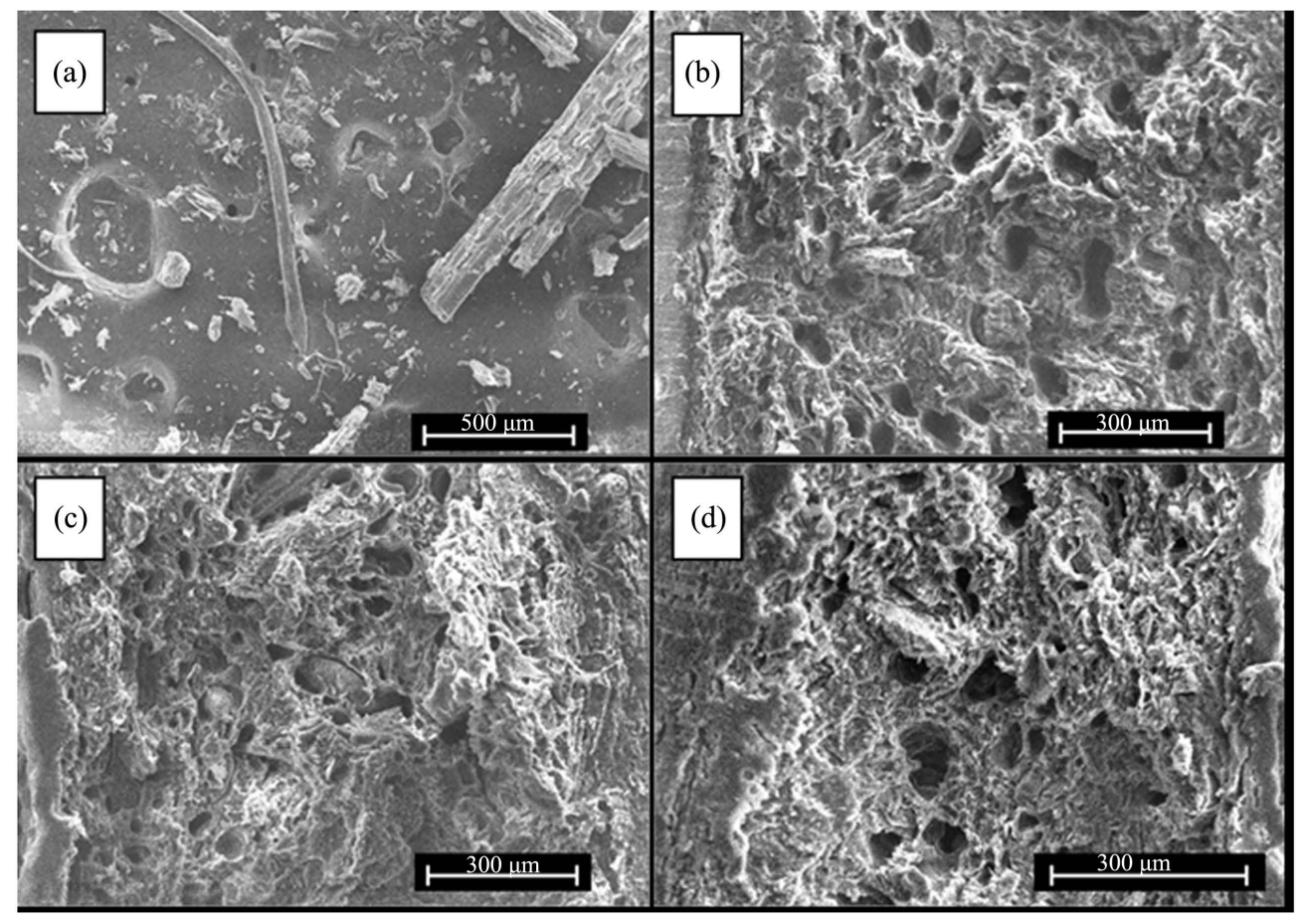

Figure 2. SEM images of PLA biocomposites: (a) TSP; (b) PLA 25TSP; (c) PLA 35TSP; (d) PLA 45TSP. 


\subsection{Thermal Analysis}

\subsubsection{Thermogravimetric Analysis}

In order to better understand the effect of the TSP on the thermal degradation of the samples, thermogravimetric analysis was used. The thermogravimetric curves for all the samples are shown in Figure 3.

TSP loses moisture around $100^{\circ} \mathrm{C}$. The onset of the degradation of TSP is around $240^{\circ} \mathrm{C}$, this degradation is mainly due to the thermal scission of hemicellulose and the glycosidic linkages of cellulose. The total mass loss percentage for TSP at $600^{\circ} \mathrm{C}$ is $70 \%$. Pure PLA demonstrates one-step degradation and the onset of the degradation was observed around $340^{\circ} \mathrm{C}$. The elaborated biocomposites presented an intermediate thermal behavior, the onset of the mass loss decrease by increasing the TSP content. The onset of degradation for the composites containing $25 \%, 35 \%$ and $45 \%$ TSP is respectively $285^{\circ} \mathrm{C}, 295^{\circ} \mathrm{C}, 302^{\circ} \mathrm{C}$. Finally, carbonization of composites was observed at $600^{\circ} \mathrm{C}$ [20] [21] [22].

\subsubsection{Differential Scanning Calorimeter (DSC) Method Analysis}

Figure 4 shows the thermograms corresponding to all samples, obtained from the heating and cooling cycles. The glass transition temperature $\left(\mathrm{T}_{\mathrm{g}}\right)$ and melting temperature $\left(\mathrm{T}_{\mathrm{m}}\right)$ of PLA were around $61^{\circ} \mathrm{C}$ and $170^{\circ} \mathrm{C}$, respectively. A decrease in the cold crystallization temperature to $100^{\circ} \mathrm{C}$ was noted (Table 1). The decrease of the cold crystallization temperature can be connected with the increase of polymer chains uniformity due to the presence of the TSP.

The $T_{g}$ does not present variations and the $T_{m}$ is very slightly reduced in the presence of TSP, however, the double melting-peak phenomenon is reduced after the adding of the powder is usual for polyesters to show the double melting-peak since the presence of crystals with different uniformity. The presence of

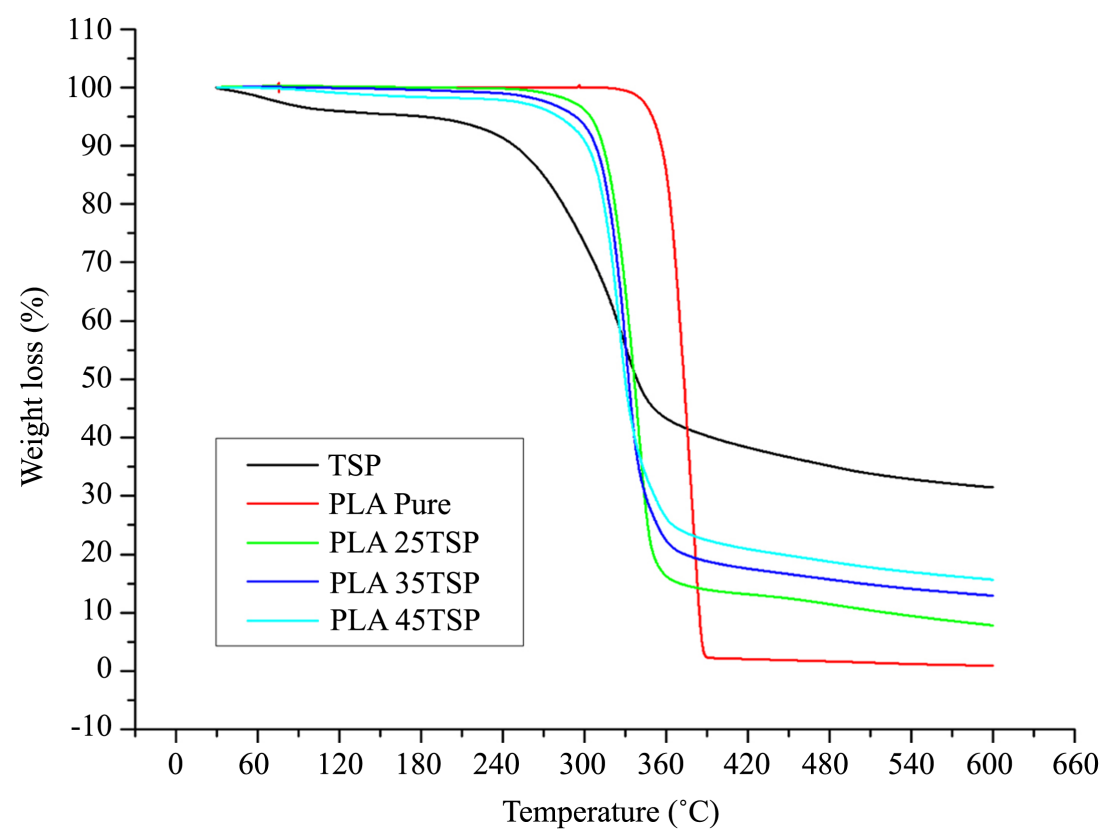

Figure 3. ATG thermograms of PLA, TSP and its composites. 


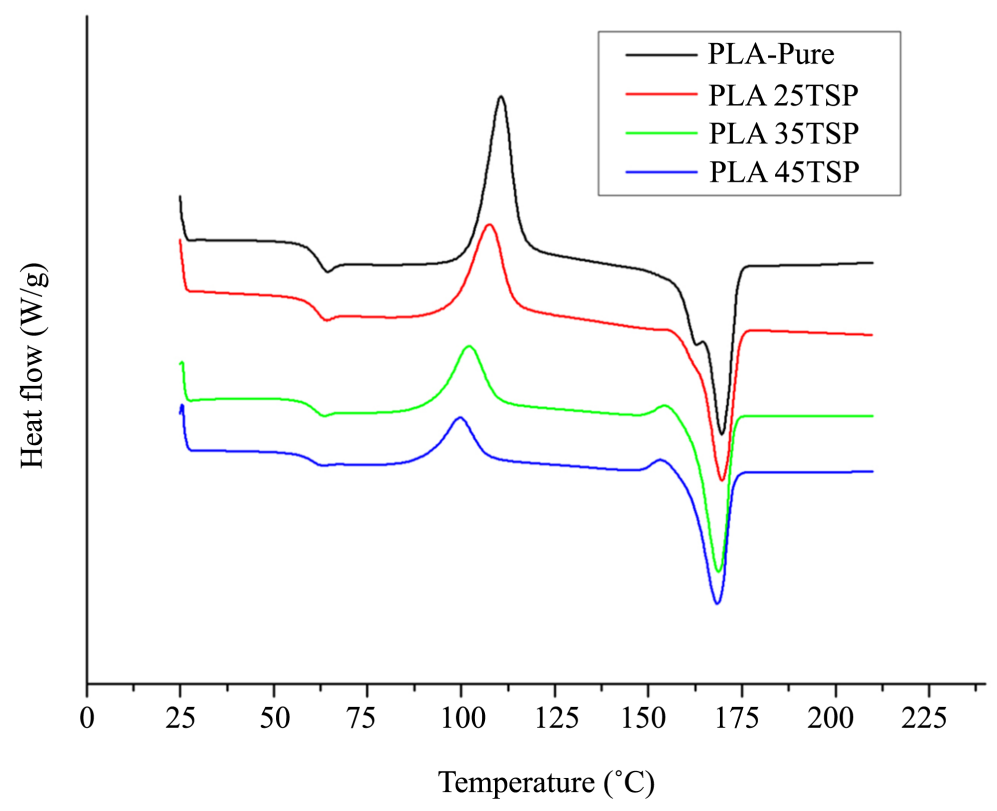

Figure 4. Fusion thermograms of biocomposites.

Table 1. Neat PLA thermal properties and its composites.

\begin{tabular}{ccccccc}
\hline Samples & $\mathrm{T}_{\mathrm{g}}\left({ }^{\circ} \mathrm{C}\right)$ & $\mathrm{T}_{\mathrm{c}}\left({ }^{\circ} \mathrm{C}\right)$ & $\mathrm{T}_{\mathrm{m}}\left({ }^{\circ} \mathrm{C}\right)$ & $\Delta \mathrm{H}_{\mathrm{c}}(\mathrm{J} / \mathrm{g})$ & $\Delta \mathrm{H}_{\mathrm{m}}(\mathrm{J} / \mathrm{g})$ & $\mathrm{X}_{\mathrm{C}}(\%)$ \\
\hline PLA Pure & 61 & 111 & 170 & 27 & 31 & $4 \%$ \\
PLA 25TSP & 61 & 108 & 170 & 18 & 27 & $12 \%$ \\
PLA 35TSP & 61 & 102 & 169 & 13 & 26 & $22 \%$ \\
PLA 45TSP & 61 & 100 & 168 & 8 & 23 & $30 \%$ \\
\hline
\end{tabular}

a single peak in the biocomposites can be explained by the lowering of the mobility of PLA chains, compared with neat PLA. Moreover, this explanation is also consistent with the reduction of the temperature of cold crystallization and the increase of the degree of crystallinity (Table 1), which highlights an increase in the order of PLA chains [21].

\subsection{Rheological Behavior}

Figure 5 represents the complex plane variations for the neat PLA and the PLA composites. As introduced above, an extrapolation of the circle arc constructed on the complex graph allows us to determine the Newtonian viscosity. Table 2 reports the Newtonian values determined for all the samples. These values show an increase in the viscosity of PLA 25TSP that is 76\% higher than virgin PLA. Though, an increase in the quantity of the charge causes a reduction of the viscosity, reaching a Newtonian viscosity value, for the sample PLA 45TSP, comparable with that measured for PLA Pure with a difference of about $6 \%$ more. The changing of the viscosity is caused by the perturbation of the normal polymer flow since the filler particles hinder the mobility of chain segments. Moreover, great changes are observed for the samples loaded regarding the reference 


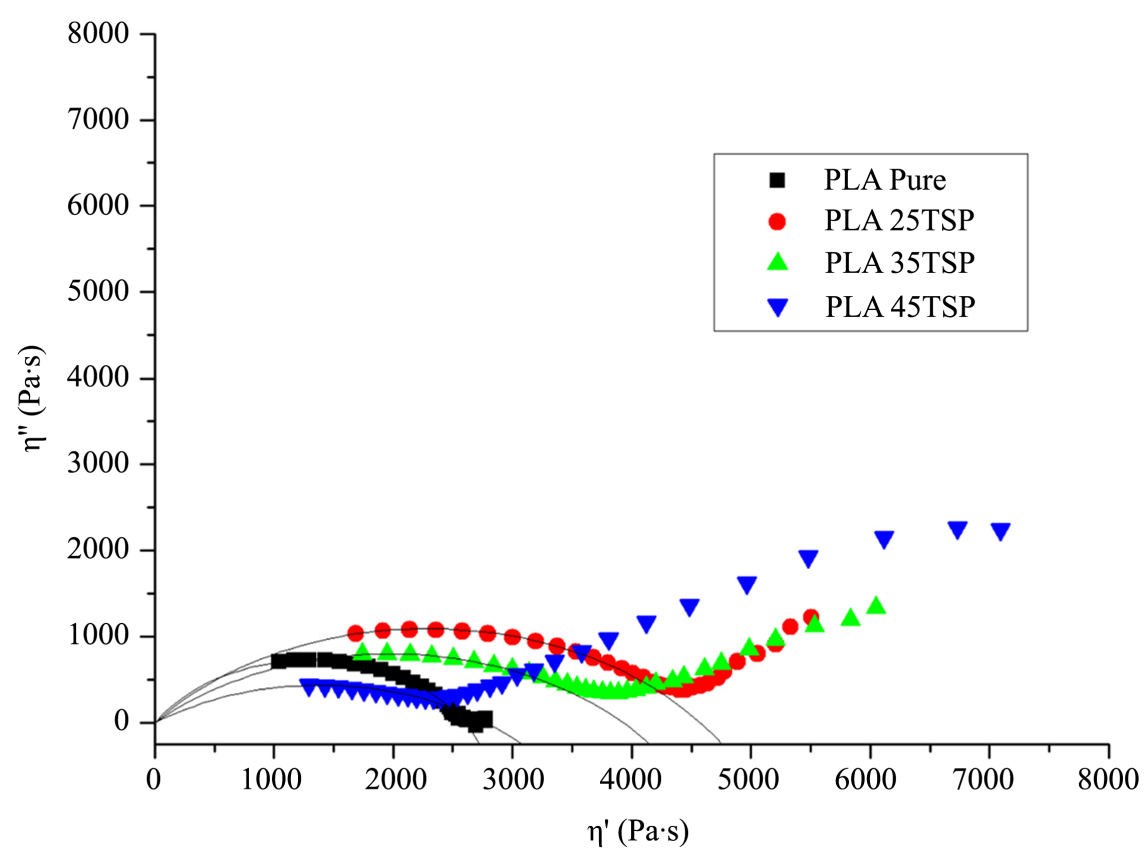

Figure 5. Complex plane diagrams for all the composites at $\mathrm{T}=180^{\circ} \mathrm{C}$.

Table 2. Newtonian viscosity values.

\begin{tabular}{cc}
\hline Samples & $\eta$ o (Pa s) \\
\hline PLA Pure & 2606 \\
PLA 25TSP & 4576 \\
PLA 35TSP & 3929 \\
PLA 45TSP & 2780
\end{tabular}

PLA Pure. All the samples with the natural fillers exhibit a deviation to the circular behavior promoting the shift of the Newtonian plateau to the low frequencies. This is characteristic of a gel behavior, indicating that at different concentrations of the powder, the level of interaction between the matrix and the filler is different at different frequencies applied [23]. In fact, at low frequencies, the viscosity strongly increases with the Typha powder content, as evidenced by the storage module of composites ( $G^{\prime}$ ) (Figure 6) since $G^{\prime}$ is higher than pure matrix due to the intrinsic rigidity of TSP. Shear-thinning behavior of the molten mass was observed, the viscosity of the composites is strongly influenced by the shear rate. The storage modulus, especially for the highest powder content, shows that the matrix transfers great stress to the filler and based on G' data, serving as the measure of elastic behavior, we can conclude that with the addition of the TSP the solid-like behavior for all the samples clearly increases [21].

\subsection{Mechanical Properties of Biocomposites PLA/Typha Stem}

The mechanical tensile properties (Young's modulus, maximum strain, ultimate tensile strength) of the biocomposites are presented in Table 3 and Figure 7. It 


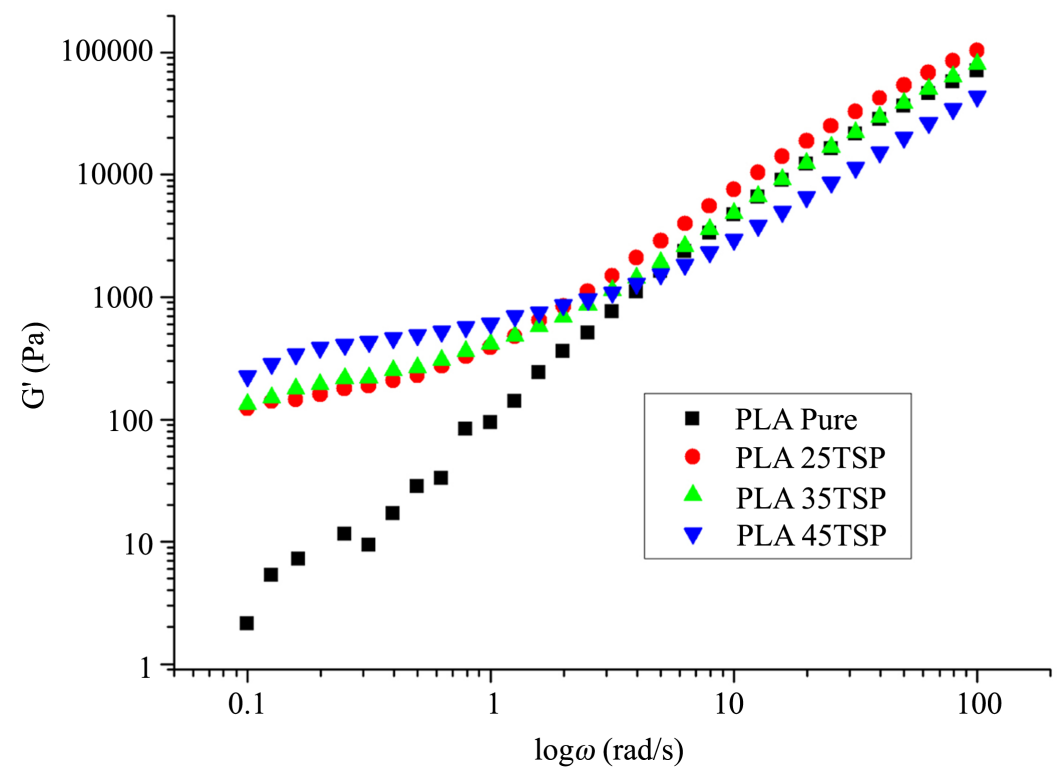

Figure 6. Frequency variations of storage $G^{\prime}$ for pure PLA and its composites at $T=$ $180^{\circ} \mathrm{C}$.

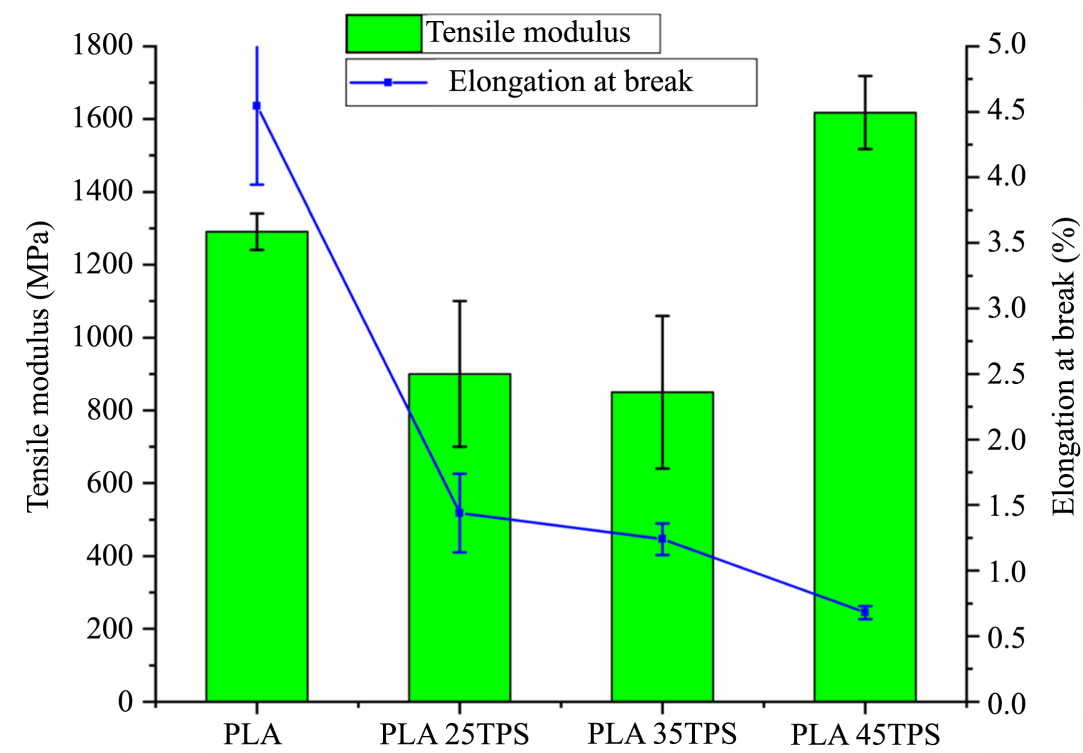

Figure 7. The tensile modulus and elongation at break as a function of TSP concentration.

Table 3. The results of tensile mechanical tests.

\begin{tabular}{cccccc}
\hline \multirow{2}{*}{ Samples } & $\begin{array}{c}\text { Young's } \\
\text { modulus }\end{array}$ & $\begin{array}{c}\text { Ultimate } \\
\text { Tensile Strength }\end{array}$ & $\begin{array}{c}\text { Breaking } \\
\text { Strength }\end{array}$ & $\begin{array}{c}\text { Deformation } \\
\text { at break }\end{array}$ & $\begin{array}{c}\text { Maximum } \\
\text { strain }\end{array}$ \\
\cline { 2 - 6 } & $\mathrm{MPa}$ & $\mathrm{MPa}$ & $\mathrm{MPa}$ & $\%$ & $\%$ \\
\hline PLA Pure & $1291.0 \pm 45$ & $38.0 \pm 3.1$ & $4.0 \pm 1.1$ & $4.6 \pm 0.6$ & $15.0 \pm 0.9$ \\
PLA 25TPS & $900.0 \pm 198$ & $8.0 \pm 4.1$ & $1.4 \pm 0.6$ & $1.4 \pm 0.3$ & $0.5 \pm 0.5$ \\
PLA 35TPS & $850.0 \pm 211$ & $6.0 \pm 3.5$ & $1.1 \pm 1.8$ & $1.2 \pm 0.1$ & $2.2 \pm 0.1$ \\
PLA 45TPS & $1618.0 \pm 112$ & $6.0 \pm 2.6$ & $0.6 \pm 0.1$ & $0.7 \pm 0.1$ & $1.3 \pm 0.3$ \\
\hline
\end{tabular}


is noted a decrease in Young's modulus of biocomposites containing 25\% and $35 \%$ of TSP compared to virgin polymer. However at $45 \%$, there is a clear increase of the module due to the intrinsic rigidity of TSP and also with the high wood content (the latter having high tensile properties), these tensile properties of the composite were improved. Decreases in the modulus observed for samples containing $25 \%$ and $35 \%$ could be caused by the inhomogeneity of the powder consisting of particles as observed in the morphological characterization section. This lowering is certainly related to the formation of aggregates and the piling up of the fibers against each other, phenomena that favor the formation of defects. At high fiber proportions, the molten mixture is very viscous and appears as "dry" and this promotes friction between fibers and contributes to the creation of pores and cavities at the interface. As a result, the fiber/matrix contact area is reduced resulting in poorer stress transfer.

\section{Conclusion}

This work has shown that the Typha stem powder can be used in PLA matrix as a reinforcing agent. Experimental results showed an increase in rheological properties after the addition of the TSP. In fact, the viscosity increase compared with pure matrix, mainly at low frequencies. The results of the thermal analysis also revealed an increase in the degree of crystallinity without a significant change in melt properties and transition temperature. The SEM morphology exhibited the presence of pores between the two phases indicating that the motion of PLA molecules was restricted by poor interfacial compatibility. The morphologic results are congruent with the mechanical characterization that not show a clear improvement of the mechanical properties for the samples containing the 25 and 35 (wt\%), however, the biocomposite containing 45\% of Typha powder have tensile properties superior to virgin PLA that could be explained by the intrinsic rigidity of TSP that with a high percentage allows the reduction of the gap between the TSP powders and the polymer matrix.

\section{Conflicts of Interest}

The authors declare no conflicts of interest regarding the publication of this paper.

\section{References}

[1] Lewandowski, K., Piszczek, K., Zajchowski, S. and Mirowski, J. (2016) Rheological Properties of Wood Polymer Composites at High Shear Rates. Polymer Testing, 51, 58-62. https://doi.org/10.1016/j.polymertesting.2016.02.004

[2] Fisher, E.W., Sterzel, H.J. and Wegner, G. (1973) Investigation of the Structure of Solution Grown Crystals of Lactide Copolymers by Means of Chemical Reactions. Colloid and Polymer Science, 251, 980-990. https://doi.org/10.1007/BF01498927

[3] Bailon, J.P. and Dorlot, J.M. (2000) Materials. 3rd Edition, Polytechnic International Press, Montreal, $736 \mathrm{p}$.

[4] Ndiaye, D. (2012) Contribution to the Study of the Characterization, Macromole- 
cular Physico-Mechanical Properties and Photo Aging Process of Polymer Wood Composites. Ph.D. Thesis, Université Cheikh Anta Diop de Dakar, Dakar.

[5] Ray, S.S. and Okamato, M. (2003) Biodegradable Polylactide and Its Nanocomposites: Opening a New Dimension for Plastics and Composites. Macromolecular Rapid Communications, 24, 815-840. https://doi.org/10.1002/marc.200300008

[6] Schwartz, B.S., Parker, C.L., Hess, J. and Frumkin, H. (2011) Public Health and Medicine in the Age of Energy Scarcity: The Case of Petroleum. American Journal of Public Health, 101, 1560-1567. https://doi.org/10.2105/AJPH.2010.205187

[7] Raquez, J.M., Habibi, Y. and Murariu, M. (2013) Polylactide (PLA)-Based Nanocomposites. Progress in Polymer Science, 38, 1504-1542.

https://doi.org/10.1016/j.progpolymsci.2013.05.014

[8] Granda, L., Espinach, F., Tarrés, Q., Méndez, J., Delgado-Aguilar, M. and Mutjé, P. (2016) Towards a Good Interphase between Bleached Kraft Softwood Fibers and Poly (Lactic) Acid. Composites Part B: Engineering, 99, 514-520.

https://doi.org/10.1016/j.compositesb.2016.05.008

[9] Scaffaro, R., Botta, L., Maio, A. and Gallo, G. (2017) PLA Graphene Nanocomposite Nanoplatelets: Physical Properties and Release Kinetics of an Antimicrobial Agent. Composites Part B: Engineering, 109, 138-146. https://doi.org/10.1016/j.compositesb.2016.10.058

[10] Qi, Z., Xu, J., Guo, B., Chen, J. and Ye, H. (2013) Improved the Thermal and Mechanical Properties of Poly (Butylene Succinate-co-Butylene Adipate) by Forming Nanocomposites with Attapulgite. Colloids and Surfaces A: Physicochemical and Engineering Aspects, 421, 109-117. https://doi.org/10.1016/j.colsurfa.2012.12.051

[11] Herc, A.S., Włodarska, M., Nowacka, M., Bojda, J., Szymański, W. and Kowalewska, A. (2020) Supramolecular Interactions between Polylactide and Model Cyclosiloxanes with Hydrogen Bonding-Capable Functional Groups. Express Polymer Letters, 14, Article No. 134.

[12] Diatta, M.T., Gaye, S., Thiam, A. and Azilino, D. (2011) Détermination des propriétés thermo-physique et mécanique du Typha australis. Congrès Français de Thermique, Perpignan.

[13] Comprendre Les Enjeux De L’Agriculture. http://www.willagri.com/2017/10/23/typha-transformer-plante-envahissante-source -denergie/

[14] Haafiz, M.M., Hassan, A., Zakaria, Z., Inuwa, M.I., Islam, M.S. and Jawaid, M. (2013) Properties of Polylactic Acid Composites Reinforced with Oil Palm Biomass Microcrystalline Cellulose. Carbohydrate polymers, 98, 139-145. https://doi.org/10.1016/j.carbpol.2013.05.069

[15] Liu, D.Y., Yuan, X.W., Bhattacharyya, D. and Easteal, A.J. (2010) Characterisation of Solution Cast Cellulose Nanofibre-Reinforced Poly (lactic acid). Express Polymer Letters, 4, 26-31. https://doi.org/10.3144/expresspolymlett.2010.5

[16] Dorlot, J.M., Baïlon, J.P. and Masounave, J. (1986) Des matériaux. 24-44 Éditions, Polytechnique de Montréal, Montréal.

[17] Ndiaye, D., Diop, B., Thiandoume, C., Fall, P.A., Farota, A.K. and Tidjani, A. (2012) Morphology and thermo mechanical properties of wood/polypropylene composites. Polypropylene, 4, 730-738.

[18] Ponnukrishnan, P., Chithambara Thanu, M. and Richard, S. (2014) Mechanical Charactreisation of Typha domingensis Natural Fiber Reinforced Polyester Composites. American International Journal of Research in Science, Technology, Engineering \& Mathematics. 6, 241-244. 
[19] Zhang, L., Lv, S., Sun, C., Wan, L., Tan, H. and Zhang, Y. (2017) Effect of MAHg-PLA on the Properties of Wood Fiber/Polylactic Acid Composites, Polymers, 9, 591. https://doi.org/10.3390/polym9110591

[20] Mofokeng, J.P., Luyt, A.S., Tábi, T. and Kovács, J. (2011) Comparison of Injection Moulded, Natural Fibre-Reinforced Composites with PP and PLA as Matrices. Journal of Thermoplastic Composite Materials, 25, 927-948. https://doi.org/10.3390/polym9110591

[21] Ma, P., Jiang, L., Ye, T., Dong, W. and Chen, M. (2014) Melt Free-Radical Grafting of Maleic Anhydride onto Biodegradable Poly (Lactic Acid) by Using Styrene as a Comonomer. Polymers, 6, 1528-1543.

https://doi.org/10.3390/polym6051528

[22] Jozwiak, L., Kazimierski, P. and Tyczkowski, J. (2017) Plasma Deposited Thin Iron Oxide Films as Electrocatalyst for Oxygen Reduction Reaction in Proton Exchange Membrane Fuel Cells. Materials Science (Medžiagotyra), 23, 1392-1320. https://doi.org/10.5755/j01.ms.23.1.14406

[23] Askanian, H., Verney, V., et al. (2015) Wood Polypropylene Composites Prepared by Thermally Modified Fibers at Two Extrusion Speeds: Mechanical and Viscoelastic Properties. Holzforschung, 69, 313-319.

https://doi.org/10.1515/hf-2014-0031 